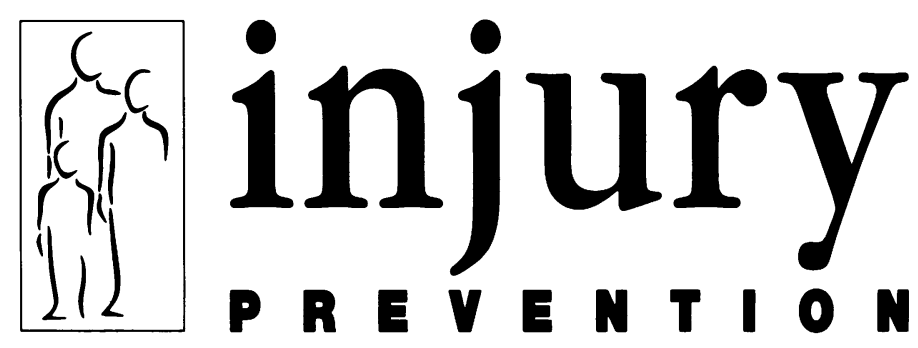

Journal of the International Society for Child and Adolescent Injury Prevention

\title{
Editorials
}

\section{Logo and logic}

Last summer, as the initial plans for the journal were being finalized, I spent some time agonizing over our choice of logo. The BMJ Specialist Journal group, under the thoughtful guidance of Alex Williamson, came up with a design that was appealing but, in my view, misleading. I thought the first design proposed gave the impression of a pregnant male adolescent. The next iteration was an improvement but unlike what was intended, it still seemed that the tallest figure represented a parent of the two smaller figures, obviously children.

We did not want the logo to convey the idea that preventing injuries to children and adolescents is mainly the parent's responsibility. This was too close to 'blaming the victim'. Consequently, the tallest figure was shrunken still more and is now, I hope, sufficiently ambiguous so that most will see it as an adolescent.

But the purpose of this editorial is not to explain the intricacies of logo design and creation. Rather, it is to examine two basic issues that relate to my editorial philosophy. I hope they reflect that of the board and most readers; if they do not, please write and explain your disagreement.

Many are troubled when society places the main responsibility for child safety on parents and assumes little or none themselves. In the past, and too often still, the popular approach to prevention bombarded parents with a seemingly endless list of do's and don't's. Clearly, these actions are a part of the answer, but, we believe, an increasingly small part. Only when a community has done all it can to ensure that its streets, playgrounds, homes, schools, and products are as safe as the best research shows they can be, is it fair and reasonable to expect parents to do all they can.

Nevertheless, it would be foolish and misleading to suggest that parents do not have an important part to play in protecting their children and adolescents from injury. Logic demands that we acknowledge that effective injury control, especially among the high risk preschool age group, will always require some level of parent supervision. But logic also demands that we appreciate fully how difficult it is for many parents to provide such constant surveillance. It is particularly difficult for poor families, where there is overwhelming evidence that injuries are much more frequent. Some have suggested that the high rate occurs because poor parents are less well educated about safety matters; others suggest it is because they provide less supervision and imply that this means they care less for their children! As offensive as this is, the question of how much supervision can realistically be expected, especially when both parents work, whether they be rich or poor, demands further study.

Equally compelling is the need for more research to examine the alternative explanation for the excess of injuries among the poor - that these families live in more dangerous environments, for example, that their streets are busier and less well policed; that their playgrounds are less well constructed; and that their homes lack the best safety measures. The list of inequities is depressingly long. In the end, good research should help us achieve a more equitable balance between the message intended by our logo and the demands of cool logic.

Another, more subtle message of our logo is conveyed by the choice of colours. Traditionally, red tells children when there is danger and green says it is safe. But this, too, often defies logic. A personal example may help illustrate my point.

I had the good fortune to be in London for one of the many meetings held to plan the conference at which the journal was launched. Later that day I was hit by a car. Despite having lived in London on and off for nearly eight years, I made the typical tourist's mistake of looking left rather than right - the equivalent of mistaking a red signal for a green. The next thing I knew I was up on the bonnet and then down on the pavement, stunned and in pain. As soon as I realized I was still reasonably intact my first thought was, 'What a wonderful story for an editorial!' The story is not so much what happened, but why.

For example, in the light of some correspondence (and, I hope, future columns) about terminology, I wondered if this was an 'accident' or an 'injury'? Could it have been prevented and if so, who was most at fault - me, or the driver? Because it was not reported to the police, I also wondered what it tells us about official 'road accident' statistics that depend on police reports? Finally, I wondered if it added some evidence to the view that preventive behaviours are clustered?

It was an 'accident' because I was unlucky enough to have happened to step on the road as a car was approaching. It was an 'injury' because I was hurt and what happened 
was preventable. Had I looked to the right (or seen a red light), I would have stopped and allowed the car to pass. Much more importantly, a serious injury was prevented because the car was moving very slowly. The driver told me he began braking the moment he saw me turn my head in the wrong direction. As a result, his speed was probably less than 10 miles per hour.

Why was he going so slowly? Having been knocked senseless, I didn't have the wit to ask but I do recall it was raining, it was dusk, and he had a child in the front seat who was well secured in an excellent baby seat! (I even congratulated him for doing so.) It occurred to me that perhaps drivers wise enough to use car seats for their infants are also those who drive slowly when it is dusk and raining, as they are advised. But I wish I had asked him whether he was aware of, and responding to, Oxfordshire's excellent campaign. Its message is 'Speed kills. Kill your speed' and its posters include the bold statement, 'If you can't stop in time, you're going too fast'. I could not agree more! It also reminds Britishers that the number of children who die after being hit by a car is directly related to its speed: at $20 \mathrm{mph}-20 \%$; at $30 \mathrm{mph}-50 \%$; and at $40 \mathrm{mph}-80 \%$.

Hence, my final questions: How assiduously do police in Britain and elsewhere enforce speed limits? How severe are the penalties for speeding and other such infractions? And what pressure, if any, is exerted on police by health departments to enforce and punish offenders based on the logic that injuries are a preventable health problem like any other?

Logos are one thing; logic another. We need both.

\section{Giving birth ... and thanks}

Launching a new journal is, I imagine, like having a baby. It involves a similar period of gestation, during which there is continuously mounting anxiety over the health of the offspring. This conception began with Mike Hayes of CAPT and Alex Williamson, responsible for the BMJ Specialist Journals. At the risk of mixing or stretching the metaphor, Mike deserves credit for planting the seed with Alex; she then sought and received Richard Smith's enthusiastic support and encouragement and that of the board. (I can't decide how to fit these actions into the metaphor.)

Then, even after what appears to be a healthy child is born, most good parents continue to worry about the future. Perhaps it is because we have so many worried parents - our entire, large, and diverse editorial board this baby's future looks bright. Virtually each member of the board has performed at least one specific act to help ensure that the contents of this issue are of acceptable, if not superior, calibre.

Apart from parents, however, others are involved in a successful childbirth, akin to the midwife or obstetrician. I want to acknowledge the efforts of the many others who assisted in delivering this somewhat postmature child: Sue Heels, who ensured that everyone appeared to be writing the Queen's English flawlessly; Julie Halfacre who enlisted subscribers beyond ourselves and our immediate families; Jane Rowlands at the BMA library who helped produce the citation list; and Ann Arnold, who kept our manuscript turnaround time at what I suspect may be a record low. Some of the credit is shared with the geniuses who invented modems and fax machines but most credit must go to the list of contributors willing to 'have a go' with a spanking new, promising, but untested journal. My warmest thanks to all. 